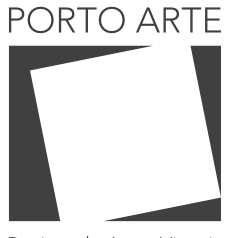

Revista de Artes Visuais

v. 25 n. 44

\title{
A Clínica do Corpo sem Órgãos: Esquizoanálise e Esquizodrama
}

The Clinic of the Body without Organs: Schizoanalysis and Schizodrama

\section{Domenico Uhng Hur}

ORCID: 0000-0002-6766-7024

Universidade Federal de Goiás, Brasil

\section{Resumo}

O objetivo deste artigo é investigar o conceito de Corpo sem Órgãos (CsO), para discutir possíveis contribuições para a clínica em esquizoanálise e no esquizodrama. Como método, revisamos toda a obra de Deleuze e Guattari para conhecer como o conceito é tratado na esquizoanálise. Cartografamos as diversas concepções sobre o CsO ao longo de sua obra. Elaboramos um esquema para pensar como podemos operacionalizar a dinâmica entre os quatro corpos (CsO, Corpo Cheio, Corpo Esvaziado e Corpo Canceroso) no campo da clínica.

Palavras-chave

Esquizoanálise. Esquizodrama. Clínica. Deleuze. Guattari.

\section{Abstract}

The aim of this article is to investigate the concept of Body without Organs (BwO), to discuss some contributions to the clinic in schizoanalysis and schizodrama. As a method, we reviewed the entire work of Deleuze and Guattari to know how the concept is treated in schizoanalysis. We mapped the different conceptions about BwO throughout their work. We elaborated a scheme to think about how we can operationalize the dynamics between the four bodies (BwO, Full Body, Empty Body and Cancer Body) in the field of the clinic.

Keywords

Schizoanalysis. Schizodrama. Clinic. Deleuze. Guattari. 


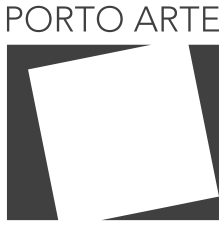

Revista de Artes Visuais

v $25 n .44$

Jul/dez 2020 e-ISSN: 2179-8001

A esquizoanálise é um campo de saberes e práticas que articula conhecimentos de diversas disciplinas e tem múltiplas definições. Pragmática Universal, Filosofia da diferença, Micropolítica, Estratoanálise, Nomadologia, Utopia Ativa, Pop análise, são alguns dos termos utilizados e ou cunhados por seus criadores (DELEUZE; GUATTARI, 1980a) e estudiosos. Não se restringe a uma epistemologia e a uma ontologia tal como os saberes acadêmicos tradicionais. Atualiza um paradigma ético-estético-político que visa potencializar e produzir vida em suas diversas atualizações.

Uma das críticas que recebe é que por sua difícil conceituação, pode se aproximar mais de um campo poético, do que prático, como se restringisse mais ao campo da semântica e não da pragmática. Entretanto, essa afirmação é equivocada, pois Deleuze e Guattari continuamente afirmam o primado pragmático de sua teoria, que sempre deve estar agenciada ao mundo e produzir efeitos. Não é mera ideologia, poesia, ou busca por adjetivações. Não atua no campo da semântica, expressando metáforas, ou novos adjetivos, mas é uma pragmática. Busca incitar, agenciar, produzir processos, para intervir e transformar a vida. Por isso não se preocupa com uma suposta essência das coisas, ou o que as coisas são. Senão como os processos funcionam, maquinam, fluem. Deste modo, podemos afirmar que é um campo de saberes e práticas que tem como finalidade a análise da propagação de fluxos das diversas materialidades da vida. Estas podem ser de diferentes tipos: semióticas linguísticas, afecções, intensidades, processos assignificantes, maquínicos, agenciamentos e composições entre os corpos etc.

Já o esquizodrama, campo criado por Gregorio Baremblitt, hipertrofia a dimensão pragmática da esquizoanálise. Criou distintos dispositivos de intervenção que dramatizam seus conceitos filosóficos. Elaborou diversas máquinas de raspagem e desterritorialização, algumas de intensidades mais baixas, outras com intensidades muito mais elevadas. Possui cinco klínicas principais: caos, cosmos, desordem; acontecer-devir; diferença-repetição; produção de produção, reprodução e antiprodução; e multiplicitação dramática (BAREMBLITT, 2019). Utiliza o termo klínica, e não clínica, para diferenciar-se da tradicional acepção de clínica, a qual se refere ao inclinar-se sobre o leito de um acamado. Inspirado na definição de clinos e clinamen de filósofos atomistas, do movimento das partículas subatômicas, que ao se chocarem produzem desvios em suas rotas, Baremblitt concebe a klínica ${ }^{1}$ como o espaço de encontro e produção de diferenças.

Um dos conceitos mais utilizados e de difícil compreensão da esquizoanálise é o de Corpo sem Órgãos (CsO), fenômeno que também é uma das principais finalidades do esquizodrama. Neste texto, para desenvolver a faceta prática da esquizoanálise, buscaremos trabalhar a dimensão pragmática deste conceito para a clínica, não ficando restritos à sua definição e discussão filosófica. Dessa forma, o objetivo deste artigo é investigar o conceito de Corpo sem Órgãos (CsO), para discutir possíveis contribuições para a teoria da técnica na clínica em esquizoanálise e no esquizodrama.

Como método procedemos com uma análise sobre toda a obra de Deleuze e Guattari para investigar como o conceito é tratado na esquizoanálise. Também realizamos uma revisão bibliográfica sobre a obra de sucessores de Deleuze e Guattari, como 


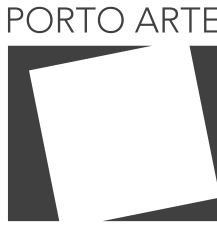

Revista de Artes Visuais $25 n .44$ Jul/dez 2020 e-ISSN: 2179-8001

Gregorio Baremblitt, entre outros. No entanto, em nossa discussão, privilegiamos as passagens trazidas pelos criadores da esquizoanálise, visto que há um grande volume de produções sobre este conceito. A partir desta leitura, cartografamos as concepções sobre o CsO e o figuramos num esquema para pensar como podemos operacionalizá-lo no campo da clínica.

\section{CsO: definições}

O conceito de CsO é retratado de formas distintas na obra de Deleuze e Guattari. É trabalhado primeiramente na Lógica do Sentido (DELEUZE, 1969). Recebe um desenvolvimento no Anti-Édipo (DELEUZE; GUATTARI, 1972), mas posteriormente assume sua 'forma final', e mais 'popularizada' nos Mil Platôs (DELEUZE; GUATTARI, 1980c), a qual também é retomada em Francis Bacon - Lógica da sensação (DELEUZE, 1981a). Vale destacar que o conceito também é citado em outras obras de Deleuze e Guattari.

No Brasil, o CsO é tratado em dezenas de trabalhos nas mais distintas áreas, como na Filosofia (RAMACCIOTTI, 2012; SCHÖPKE, 2017), Psicologia (RESENDE, 2008; RANGEL, 2019), Medicina (TEIXEIRA, 2004), Educação (MOSSI; OLIVEIRA, 2015), Literatura (SANDRINI, 2017), Artes cênicas (CAETANO, 2012; MAOILEARCA, 2019), Dança (BOM-TEMPO; SALMIN, 2018), Arquitetura (RODRIGUES, 2012), Educação ambiental (GAUTHIER, 2013) etc. De forma geral estes trabalhos tratam da desterritorialização, reinvenção e redefinição dos processos em seus distintos campos, proporcionando uma discussão em que o conceito de CsO agencia e inspira suas reflexões e fazeres.

O CsO é um conceito que está na interface entre a arte e a clínica. Deleuze e Guattari, em seus escritos, têm o hábito de citar autores da Literatura, da Arte, como forma de figurar e devir os seus conceitos e reflexões. Inclusive alguns dos seus conceitos recebem até maior inspiração da Arte do que da Ciência, ou da Filosofia. A famosa proposição de sociedade de controle (DELEUZE, 1992) é, por exemplo, mais tributária da Literatura. Para sua constituição, Deleuze discute as alterações no trabalho, das máquinas técnicas, na história da filosofia, a transição de elementos na química (do carbono ao silício), mas só se convence da mudança a um novo diagrama social, ao ler sobre essa maquinaria de controle num artigo do escritor beatnik, marginal, drogado, queer, William Burroughs (DELEUZE, 1986a; HUR, 2018a).

Para desenvolver o conceito de $\mathrm{CsO}$, Deleuze e Guattari se referenciam na obra do artista e diretor de teatro Antonin Artaud, mais especificamente na emissão radiofônica "Para acabar com o juízo de Deus". Nela Artaud, bem como em toda sua obra, faz uma ácida crítica à moral, América, dinheiro, Deus. Artaud costuma denunciar os grandes estratos que bloqueiam os movimentos, as forças, ao que chama de caca. Flávia Soares (2018), em sua dissertação de mestrado "O corpo anárquico na obra de Antonin Artaud: [des]encarceramento e crueldade na sociedade contemporânea", identifica estes estratos bloqueadores nos escritos de Artaud como a consciência, a alma e o organismo. Estratos que encarceram o corpo, que diminuem a potência da vida. Então, Artaud, com seu CsO, não combate o corpo, tampouco os órgãos, mas sim o que o bloqueia: o organismo, a organização estratificada dos objetos parciais, das máquinas-órgãos, do 


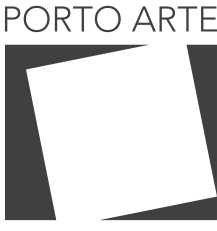

Revista de Artes Visuais

$\vee 25 n .44$ $\mathrm{Jul} / \mathrm{dez} 2020$ e-ISSN: 2179-8001

corpo. Há uma luta contra a organização e o organismo instituído que bloqueiam as potências da vida. Por isso que clama por um corpo formado de "sangue, fogo e ossos" (ARTAUD, 1947), que combata o Julgamento de Deus. Circulação, intensidades e estrutura. Energia e força. Fogo que queima e brilha, que produz acontecimentos.

Deleuze (1969), em Lógica do Sentido, busca pensar esse corpo sem órgãos, intensivo, a partir da experiência esquizo. Há nele uma modalidade de processamento que rompe com a superfície e que opera por um outro registro, que não é o significante:

o triunfo não pode ser obtido agora a não ser pela instauração de palavras-sopros, de palavras-gritos em que todos os valores literais, silábicos e fonéticos são substituídos por valores exclusivamente tônicos e não escritos, aos quais corresponde um corpo glorioso como nova dimensão do corpo esquizofrênico, um organismo sem partes que faz tudo por insuflação, inspiração, evaporação, transmissão fluídica (o corpo superior ou corpo sem órgãos de Antonin Artaud) (p. 91, itálico no original).

Dessa forma, ao invés de valores significantes, simbólicos, fonéticos, temos nesse corpo os valores tônicos, ou mesmo palavras sem articulação, que consideramos corresponder ao campo das intensidades e aos graus de potência (DELEUZE, 1968), ou seja, ao âmbito do assignificante. Uma fluidificação, propagação, que se refere a uma deriva do movimento, que nesse momento, Deleuze denomina como a ruptura da superfície para uma queda no abismo.

Obviamente, sem querer romantizar o processo esquizo, Deleuze (1969) compreende que há nele uma ambiguidade, um espaço paradoxal, que pode distinguir a produção de diversos corpos dessa experiência: do corpo do esquizo não resulta apenas um corpo glorioso, mas também pode resultar um corpo coador (poroso), um corpo despedaçado, ou mesmo um corpo dissociado. Então, antes de seu encontro com Guattari, o filósofo apresenta brevemente uma tipologia de distintos corpos que podem decorrer do processo esquizo e que entram em uma certa contraposição à produção de um CsO. Deleuze estipula que o corpo despedaçado, ou os órgãos despedaçados, situam-se no polo contrário ao CsO. Assim há uma dupla polaridade entre um corpo furado, o corpo do ódio, e um corpo glorioso, o corpo da plenitude. Os órgãos sem corpo (ŽIŽEK, 2006) são a antítese do corpo sem órgãos.

Para desenvolver este conceito e discutir seu funcionamento, Deleuze (1969), ainda nessa obra, estabelece um diálogo com as posições esquizo-paranoide e depressiva da psicanálise de Melanie Klein. Mas vale destacar que o filósofo não alude à posição esquizo-paranóide, senão a uma posição esquizoide, para tratar dos processos e do corpo esquizofrênico. Nesse sentido, diferentemente da tradição kleiniana (KLEIN; HEINMAN; ISAACS; RIVIERE, 1969), ele trata do processo esquizo de forma separada do processo paranoico. Compreende que a posição esquizoide, em contraposição à depressiva, não se refere à introjeção de objetos parciais, senão a “(...) um organismo 


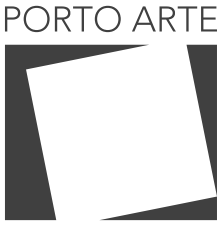

Revista de Artes Visuais

v $25 n .44$

Jul/dez 2020 e-ISSN: 2179-8001

sem partes, um corpo sem órgãos, sem boca e sem ânus (...)" (DELEUZE, 1969, p. 193).

Assim há um corpo, um espaço, de indiferenciação, no qual os limites não são precisos, com uma certa liquidez e viscosidade: “(...) o corpo sem órgãos e a especificidade líquida estão ligados no sentido de que o princípio molhado assegura a soldadura dos pedaços em um bloco, ainda que fosse um "bloco de mar'" (p. 194). Deste modo, o CsO forma blocos de coexistência entre distintos elementos, fenômeno que dará origem posteriormente ao conceito de plano de consistência, mais trabalhado nos Mil Platôs (DELEUZE; GUATTARI, 1980e).

No Anti-Édipo (DELEUZE; GUATTARI, 1972), constata-se uma acepção um pouco distinta sobre o CsO, que pode trazer certa confusão ao leitor. O CsO é tratado por dois termos distintos: Corpo sem Órgãos e Corpo pleno sem Órgãos. Estes termos discriminam processos distintos, mas que às vezes são utilizados como sinônimos pelos próprios autores. Então, em diferentes passagens, pergunta-se qual seria o CsO de uma sociedade, bem como se afirma que ela tem um corpo pleno sem órgãos. No início da obra os autores defendem que: "O corpo pleno sem órgãos é o improdutivo, o estéril, o inengendrado, o inconsumível" (DELEUZE; GUATTARI, 1972, p. 20). Depois afirmam que o CsO "reinjeta o produzir no produto" (p. 100). Consideramos que este conceito apresenta uma dupla valência, uma bipolaridade, em que de um lado, o corpo pleno sem órgãos é antiprodução, mas no outro, o CsO é produção. Para contrapor estes dois processos, neste artigo, denominamos o Corpo pleno sem Órgãos, como Corpo Cheio (CC), que é a definição que Gregorio Baremblitt (1998) adota.

Dessa forma, quando Deleuze e Guattari (1972) se questionam sobre qual é o CsO de determinada formação social, entendemos que eles perguntam qual é o seu CC. Portanto, no capítulo Selvagens, Bárbaros e Civilizados, compreendemos que eles estão cartografando qual é o CC de cada formação investigada: a máquina territorial primitiva, a formação imperial-despótica, e a máquina capitalista civilizada, ou seja, refletindo sobre seus diagramas de forças constituídos. Consideramos que, posteriormente, a ideia de CC é traduzida por Deleuze (1986a, 1986b) para a noção de diagrama, conceito criado por Michel Foucault. A utilização desse novo conceito inclusive o faz abdicar da proposição de uma História Universal, para conjecturar a transição entre distintos e diversos diagramas de forças indefinidamente (DELEUZE, 1986a), não havendo História Universal e tampouco Fim da história.

Nos Mil Platôs, o CsO não é mais associado com o improdutivo, ou a antiprodução, mas sim como uma prática, uma produção. "O corpo sem órgãos não é um corpo morto, mas um corpo vivo, e tão vivo e tão fervilhante que ele expulsou o organismo e sua organização" (DELEUZE; GUATTARI, 1980a, p. 43). O CsO traz um processo flamejante, produtivo, "que não pára de desfazer o organismo, de fazer passar e circular partículas a-significantes, intensidades puras, e não pára de atribuir-se os sujeitos aos quais não deixa senão um nome como rastro de uma intensidade" (DELEUZE; GUATTARI, 1980a, p. 12).

No platô específico sobre o CsO, Deleuze e Guattari (1980c) adotam uma narrativa um tanto insólita para se iniciar um texto filosófico, acadêmico. Partem de um programa masoquista repleto de chicotadas, costuras, agulhas, em que se visibiliza um 


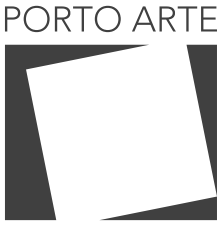

Revista de Artes Visuais

v $25 n .44$

Jul/dez 2020 e-ISSN: 2179-8001

contrato, um acordo, entre dois. Então já há uma espécie de exercício da crueldade, em trazer explicitamente algo que vislumbramos no senso comum como um tabu, uma perversão, ou até mesmo uma piada. Há uma inversão, uma torção, em que se derrete a imagem de pensamento do que é um texto de Filosofia.

O tema do masoquismo não é novo na obra deleuzeana. Em 1967 ele publicou um livro de apresentação da obra de Leopold von Sacher-Masoch. Pelo conteúdo de suas narrativas, Sacher-Masoch teve seu nome associado à entidade clínica masoquismo. Entre uma série de questões desenvolvidas nessa obra, Deleuze denuncia o mau tratamento dado ao masoquismo. Para ele, o masoquismo de forma alguma deve ser encarado como o negativo do sadismo. 0 masoquismo não é seu contrário, pois possui a sua própria singularidade. Assim é um contrassenso supor que exista uma entidade clínica denominada de sadomasoquismo, pois ambas têm uma estruturação bastante distinta. 0 masoquismo, diferente do sadismo, ao invés de ter como primado a destruição e transgressão da lei (SAFATLE, 2007), calca-se num contrato em que se faz as intensidades passarem. Um contrato no qual quem inclusive dá as consignas ao par é o próprio masoquista e não a dominatrix. 0 masoquismo opera pela associação do contrato e não pela negação da lei. Nesse sentido, o masoquismo não é apreendido como uma doença, ou perversão, como costumeiramente tratamos. É um programa, um dispositivo, uma máquina que vai gerar algo.

0 masoquismo também não deve ser apreendido como pulsão de morte. 0 corpo masoquista não deve ser tratado como um fantasma, uma metáfora, interpretado como um conjunto de significâncias e subjetivações, mas sim como um programa de experimentação. Ele não busca a dor, o retorno a um inorgânico, nem é um prazer desviado. $\mathrm{O}$ masoquismo não busca o sofrimento e a dor em si. Procura produzir um CsO, o qual só poderá ser preenchido por intensidades de dor. É como se o sofrimento fosse o preço a pagar nesse experimento. Ondas doloríferas que se comportam como matilhas, bandos, populações e que não buscam o prazer, senão colocar as forças em circulação. Há aí um desligamento do pseudo-liame do desejo com o prazer (DELEUZE; GUATTARI, 1980c). Este programa é constituído por duas etapas:

$1^{\circ}$ - Fabricar o CsO, esvaziá-lo, fazer os fluxos romperem os estratos e $2^{\circ}$ - fazer as intensidades circularem, passarem, transitarem nesse corpo.

Deleuze e Guattari (1980c) trazem outro exemplo, da construção de um agenciamento masoquista que irrompe em duas séries distintas: do cavalo e do masoquista. Nesse programa, no qual há o ato do masoquista ser atado, amarrado, tal como um cavalo, fabrica-se uma transmissão de energias, um processo de involução. Há o contágio do devir-animal do cavalo, de suas potências inatas domesticadas, ao masoquista, como forma de trabalhar (ou domesticar) suas próprias potências inatas. Decorre-se dessa máquina, uma série explosiva, que resulta no aumento de sua potência e intensidades. É uma experimentação de produção de potência, que não deve ser reduzida ao prazer e tampouco à sexualidade.

Entretanto o programa de produção do CsO nem sempre é bem-sucedido. Deleuze e Guattari (1980c) exemplificam o fracasso desse processo com um desfile de corpos lúgubres, corpos sem órgãos que se cansaram de seus órgãos e traçaram uma linha de 


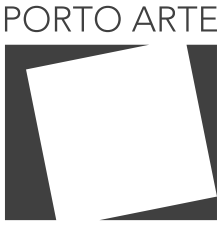

Revista de Artes Visuais

v $25 n \cdot 44$

$\mathrm{Jul} / \mathrm{dez} 2020$ e-ISSN: 2179-8001

esvaziamento de si. Corpos que realizaram apenas a primeira etapa da desterritorialização, mas que não lograram êxito em cumprir a $2^{a}$ etapa, de fazer as intensidades circularem, com que as populações ocupassem e migrassem pelo deserto do CsO. Narram toda uma atmosfera lovecraftiana. 0 corpo hipocondríaco, com seus órgãos destruídos, os corpos paranoicos, com seus órgãos atacados, o corpo esquizo, que travou uma luta anterior com a catatonia, o corpo gélido do drogado, que é um corpo esquizo experimental, que muitas vezes se afunda num buraco negro. Todos estes corpos lúgubres são corpos fraturados e não plenos, esvaziaram sem a prudência necessária. Ao invés de se tornarem um $\mathrm{CsO}$ intensivo, viraram vazios ou cancerosos. Traçaram uma linha de fuga tão intensa, que se converteu numa linha autoabolicionista.

Deleuze e Guattari (1980c) afirmam que no CsO só as intensidades passam e circulam, ele as produz e as distribui numa zona contínua de intensidades e não extensivas. O CsO não é lugar, nem representação, é prática, experimentação e produção. É uma matéria intensa e não formada, não estratificada "e tudo o que escorria sobre tal corpo, partículas submoleculares e subatômicas, intensidades puras, singularidades livres pré-físicas e pré-vitais" (DELEUZE; GUATTARI, 1980a, p. 58). É o grau zero intensivo. "Ovo pleno anterior à extensão do organismo e à organização dos órgãos" (DELEUZE; GUATTARI, 1980c, p. 13). O CsO é o desejo que produz um plano de consistência apenas ao traçá-lo, ao propagar-se. Por isso que nunca se chega a ele: é o limiar de variação intensiva.

É uma proposição difícil de se compreender, pois não se define por suas extensões, por estratos e materialidades, mas por aspectos que se referem às suas intensidades, aos seus graus de potência, "se define por eixos e vetores, gradientes e limiares, tendências dinâmicas com mutação de energia, movimentos cinemáticos com deslocamento de grupos, migrações, tudo isto independentemente de formas acessórias" (DELEUZE; GUATTARI, 1980c, p. 14). Portanto, é definido por intensidades e vetores de forças, independente das extensões que o recobrem.

Nesse sentido, o CsO é o movimento em fluxo, no qual os órgãos perdem toda constância. Ele deve ser apreendido na lógica da conexão de desejos, conjunção de fluxos, contínuo de intensidades. "O CsO é o campo de imanência do desejo, o plano de consistência próprio do desejo. 0 desejo se define como processo de produção" (DELEUZE; GUATTARI, 1980c, p. 15). É o desejo magmático que em sua propagação produz seu próprio plano de consistência.

O CsO não é inimigo do corpo, senão do organismo, daquilo que organiza e reduz a potencialidade do corpo. O organismo, o juízo de Deus, o CC, é o antípoda do CsO. É um "fenômeno de acumulação, de coagulação, de sedimentação que the impõe formas, funções" (DELEUZE; GUATTARI, 1980c, p. 21). É um estrato sobre o CsO. Estratos sobre as intensidades, camadas sobre os fluxos. Os estratos (e o Eu) se aferram ao CsO, desacelerando e diminuindo seu potencial de forças. Deleuze e Guattari (1980c) compreendem que há 3 grandes estratos bloqueadores: o organismo, a significação e a subjetivação. Nesse sentido, o CsO opõe o organismo, a significação e a subjetivação à desarticulação, à experimentação e ao nomadismo como movimento. Busca desfazer o organismo, abrir-se a conexões, composições e criações que resultem desses encontros. Visa instaurar 


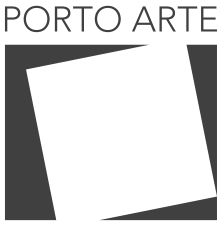

Revista de Artes Visuais

$\vee 25 n .44$ $\mathrm{Jul} / \mathrm{dez} 2020$ e-ISSN: 2179-8001

um plano de consistência que surja das fissuras da superfície de estratificação. A atualização do fluxo da duração mediante o tempo estriado cronológico (DELEUZE, 1966).

Por isso que o CsO não deve ser interpretado e sim experimentado. É uma prática e não uma metáfora. Não deve ser pensado na lógica do ser, nem da representação, mas sim na lógica do bloco do devir. Ao invés de evolução paralela entre homogêneos, evolução a-paralela entre heterogêneos = Involução. A produção de um CsO é a própria propagação do desejo, em sua concomitante produção de um plano de consistência.

\section{A clínica do CsO}

Consideramos que o conceito de $\mathrm{CsO}$ pode referenciar diretamente a prática clínica do/a psicólogo/a. Dessa forma, neste tópico desenvolvemos algumas temáticas para contribuir com a teoria da técnica esquizoanalítica e esquizodramática. Um primeiro alerta é que não se deve simplesmente dicotomizar o $\mathrm{CsO}$ ao CC, como se a produção do CsO fosse necessariamente um programa positivo de desterritorialização e o CC fosse algo negativo. Por isso Deleuze e Guattari (1980c) nos alertam que nesse movimento é fundamental e indispensável a atividade de prudência. A prudência são as rações de território, um lócus de mantimentos e terra firme, para que se possa investigar o estrato e traçar novas linhas. Um território para que o corpo não se esvazie desmedidamente e não se perca, pois a produção de um CsO pode tangenciar o falso, o alucinatório, o ilusório e a morte psíquica (DELEUZE; GUATTARI, 1980c). Nesse sentido, citam vários exemplos de territórios de prudência na literatura com Artaud e inclusive Carlos Castañeda. Encontrar um lugar, compor com seus aliados, fazer correr os fluxos, produzir os devires-animais, descobrir e lidar com novos seres (tonal e nagual), toda uma problemática que articula o CC ao CsO. Deve-se assim realizar uma cartografia, uma análise do que produz, do que circula e do que bloqueia nesse corpo. 0 que o povoa, o que passa, o que o obstaculariza? 0 que pode um corpo? Qual é a potência de um corpo?

Destacamos que nos Mil Platôs (DELEUZE; GUATTARI, 1980c) há uma nova tipologia entre distintos tipos de corpos, diferente do que é trabalhado na Lógica do Sentido (DELEUZE, 1969) e no Anti-Édipo (DELEUZE; GUATTARI, 1972). Na Lógica do Sentido havia o CsO, o corpo poroso, o corpo despedaçado e o corpo dissociado. No Anti-Édipo o CsO e o CC. Nos Mil Platôs, sem contar os corpos lúgubres supracitados há três tipos de corpos que se antagonizam ao CsO: o CC, o corpo esvaziado e o corpo canceroso.

Consideramos que o CC é aquele que constitui um circuito desejante em torno de si. Os vetores de forças são direcionados ao próprio corpo, de forma centrípeta, isto é, dirigida a um centro. Com esse investimento desejante, em que tudo é vetorizado para dentro desse corpo, passa-se a constituir um corpo voraz, um corpo inchado, um corpo cheio. Esse processo pode piorar quando as fronteiras desse CC se tornam rígidas, convertem-se em couraças, em que as trocas com o fora se tornam de certa forma obstruídas, ou obstacularizadas. As forças só circulam para o dentro, passam por um processo de entropia e a se autossufocar nesse 'interno'. Assim, esse corpo cheio pode sofrer com os processos de retenção, ou mesmo adotar procedimentos de descarga violenta, com pouca metabolização do conteúdo que está sendo expelido. No âmbito concreto 


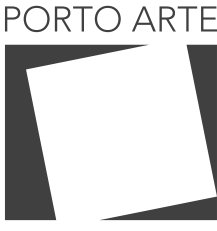

Revista de Artes Visuais

v $25 n \cdot 44$

$\mathrm{Jul} / \mathrm{dez} 2020$ e-ISSN: 2179-8001

e atualizado num indivíduo, esse CC faz com que continuamente queira ser alvo de reconhecimento, ser legitimado, amado pelos outros, sempre absorvendo, mas muitas vezes não dando nada em troca, pois os vetores de forças são apenas centrípetos. As figuras 'roliças' pintadas e esculpidas por Fernando Botero são a expressão pictórica do CC na atualidade. Não são pessoas gordas, senão enrijecidas, como se tudo girasse em torno do seu corpo e não houvesse nada para mirar no 'externo' (HUR, 2018b).

Contudo, não são produzidos apenas corpos cheios, mas também corpos esvaziados. Há a tentativa de produção de um corpo sem órgãos, mas que ficou apenas na sua primeira etapa: da desterritorialização e esvaziamento do corpo. Nesse caso faltou a prudência, não se preencheu esse corpo, não se fez passar as forças de preenchimento e propagação, atração e repulsão, na produção de uma máquina miraculante. Fabricou-se um programa de rechaço de tudo que é externo, com o máximo de porosidade para as forças centrífugas e o máximo de bloqueio para as forças centrípetas. Constitui-se um claustro em que se pretende um esvaziamento radical das intensidades. Uma política da recusa ao que pode abalar seu corpo. "Criar um deserto inabitável e vazio. Linha de fuga auto-abolicionista, autodestruição. Grau de afecção zero que gradativamente leva ao esgotamento da vida" (HUR, 2018b). Tal funcionamento pode ser visto, por exemplo, nos corpos bulímico e anoréxico.

Já o corpo canceroso é o ápice da deterioração proveniente seja do CC ou do corpo esvaziado. Na intensificação do processo de inchaço e enclausuramento do CC, ou de autoabolicionismo de um corpo esvaziado, "uma célula torna-se cancerosa, louca, prolifera e perde sua figura, apodera-se de tudo" (DELEUZE; GUATTARI, 1980c, p. 26). Ela, em conjunção com outras, pode promover processos de bloqueio da circulação dos fluxos, ou mesmo uma autoasfixia do corpo em si, um ataque às outras células e moléculas. Nos Mil Platôs não há uma teorização extensa do que é esse corpo canceroso, apenas alguns traços. Deleuze e Guattari (1980c) também estipulam uma relação desse quantum de bloqueio e destrutividade com o fascismo, que é uma máquina de guerra que toma a própria guerra como tarefa final e traça uma linha de fuga autoabolicionista, constituindo um Estado e vida suicidários.

Conjecturamos que o corpo canceroso atualiza as forças reativas e de ressentimento, características do niilismo. Ressentimento, má-consciência, vontade de nada e abolição da vida, em seu limite autoabolição (DELEUZE, 1962). Funcionamento reativo que se atualiza nas condutas destrutivas e de autoimolação na atualidade, ódio, extermínio e genocídio da diferença, vontade de abolição de si próprio.

CC, corpo esvaziado, corpo canceroso. Constata-se que são três modalidades corporais que podem empobrecer e despotencializar os indivíduos e coletivos. Por isso que devem ser criados dispositivos que possam transmutar esses corpos no caminho da produção de um CsO, intensivo, dionisíaco e orgiástico. Corpos que sejam ocupados por forças ativas de vida. Potencializados e não autointoxicados, enclausurados. Pois: 


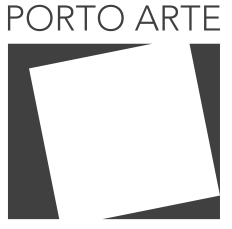

Revista de Artes Visuais

v. 25 n. 44 $\mathrm{Jul} / \mathrm{dez} 2020$ e-ISSN: 2179-8001
A tarefa da esquizoanálise é desfazer incansavelmente os eus e seus pressupostos, é libertar as singularidades pré-pessoais que eles encerram e recalcam, é fazer correr os fluxos que eles seriam capazes de emitir, de receber ou de interceptar, de estabelecer as esquizas e os cortes cada vez mais longe e de maneira mais fina, bem abaixo das condições de identidade, de montar as máquinas desejantes que recortam cada um e o agrupam com outros. (DELEUZE; GUATTARI, 1972, p. 480-481).

Consideramos que a clínica esquizoanalítica deve mapear, cartografar, os circuitos desejantes constituídos, o funcionamento das distintas máquinas e fluxos desejantes, com a finalidade de produção de linhas de fuga e processos de potencialização e de criação. Deve analisar a propagação dos vetores de forças e desejantes, fazer um mapeamento dos diagramas, das máquinas abstratas, seja no consultório privado, ou no campo institucional, comunitário e das políticas públicas. A clínica esquizoanalítica deve portar-se como uma máquina vibracional que buscar raspar os estratos coercitivos, para as intensidades circularem, e assim elevar os graus de potência do corpo e de valência social. Busca fomentar processos de raspagem e de circulação das intensidades que eliciem linhas de fuga, disrupção e desterritorialização, para a produção de um CsO.

A partir dessa discussão e categorização em quatro corpos, elaboramos o esquema expresso na Figura 1 para visibilizar a dinâmica entre eles, articulando aos processos de desterritorialização-territorialização e produção-antiprodução. Destacamos que é uma figura um tanto esquemática para assumir funções de didatismo, e não de redução dos fenômenos.

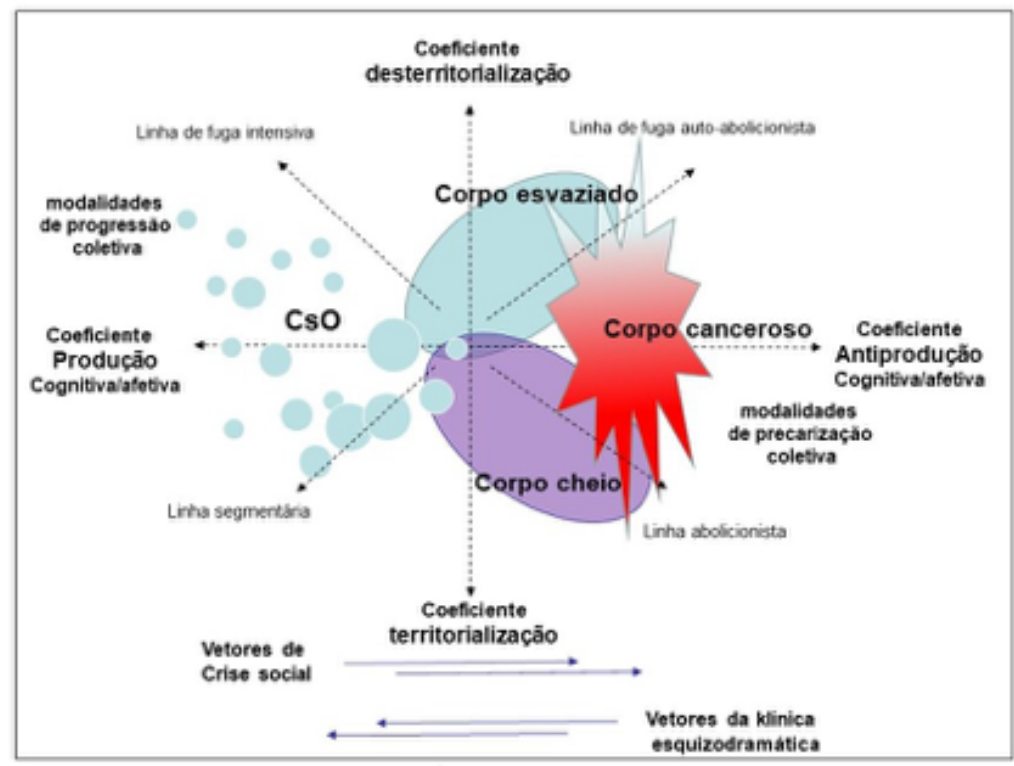




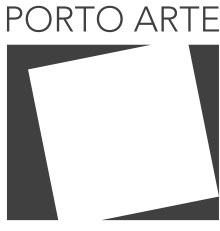

Revista de Artes Visuais

v $25 n .44$

Jul/dez 2020 e-ISSN: 2179-8001

No eixo horizontal há dois polos, o de produção e antiprodução cognitiva/afetiva. Tal como Espinosa (DELEUZE, 1981b), consideramos que os processos de potencialização corporal podem levar ao desenvolvimento das atividades de cognição/afecção como um todo, pois cognição e afecção não formam pares antitéticos, como algumas teorias clássicas da psicologia social acreditam (LE BON, 1895). Portanto, quanto maior o potencial afetivo, ou mais elevado o poder de se afetar, maiores podem ser as realizações cognitivas. Dessa forma, há processos de produção cognitiva/afetiva quando o corpo se potencializa a partir de relações de composição com outros corpos. E há o contrário, processos de antiprodução, quando o corpo se decompõe na relação com outros corpos, ou consigo próprio. Assim, evidentemente, as modalidades cognitivas se precarizam na medida em que se direcionam ao polo antiprodutivo, deixando de operar por uma lógica da pluralidade, para atuar numa lógica dicotômica, ou seja, deslocando-se de uma lógica das multiplicidades, para uma lógica da negatividade.

No eixo vertical situam-se os polos de desterritorialização e territorialização. No hemisfério superior há os processos relacionados ao que Deleuze e Guattari (1975) denominam de coeficiente de desterritorialização, enquanto no hemisfério inferior há o coeficiente de territorialização (GUATTARI, 2015). Nesse sentido, em um hemisfério há os processos relacionados aos picos de desterritorialização, à produção de um espaço liso, enquanto no outro, os lados territoriais, que proporcionam uma fixidez, base, bem como a instauração de um espaço estriado (DELEUZE; GUATTARI, 1980b; HUR, 2012).

$\mathrm{Na}$ articulação entre estes dois eixos, vertical e horizontal, constata-se que nem todo processo de desterritorialização é produtivo e nem todo processo de territorialização é antiprodutivo. Portanto, em cada quadrante há a propagação de um tipo determinado de linha. Na conjunção desterritorialização/produção, há a difusão de linhas de fuga; na intersecção territorialização/produção, linhas segmentárias; no encontro territorialização/antiprodução, as linhas abolicionistas; e na zona desterritorialização/ antiprodução, a linha autoabolicionista.

A produção de cada corpo se refere à atualização e intensificação da propagação de cada linha, a qual também pode se transmutar em seu próprio movimento de difusão. O CsO é produzido primeiramente por linhas de fuga que fraturam os bloqueios e couraças, o que permite a propagação dos fluxos. Entretanto há um segundo movimento de preencher, de ocupar e de fazer circular as populações nesse corpo. Devem ser produzidas conexões, que são uma "maneira de eliminar os corpos vazios e cancerosos que rivalizam com os corpos sem órgãos; de rejeitar as superfícies homogêneas que recobrem o espaço liso; de neutralizar as linhas de morte e de destruição que desviam a linha de fuga" (DELEUZE; GUATTARI, 1980e, p. 197).

Então, para manter seu coeficiente de produção, o cultivo do CsO se situa num espaço paradoxal entre desterritorialização e territorialização, entre idas e vindas, num ziguezague, numa relação entre linha de fuga e linha segmentária. Mas essa segmentaridade deve ser transitória, os órgãos são vistos como transientes: "o corpo sem órgãos não se define pela ausência de órgãos, não se define apenas pela existência de um órgão indeterminado; ele se define, enfim, pela presença temporária e provisória de órgãos determinados" (DELEUZE, 1981a, p. 54, itálico no original). Os órgãos são vistos 


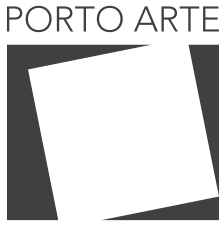

Revista de Artes Visuais

v $25 n .44$

Jul/dez 2020 e-ISSN: 2179-8001

como intensidades, pelos quais o corpo pode 'escapar', tal como retratado nos quadros de Francis Bacon. Nessa conexão e transmutação entre estrato e fluxos, a máquina é sempre máquina da máquina (DELEUZE; GUATTARI, 1975).

Caso não haja a constituição dessa zona paradoxal, corre-se o risco que a criação do $\mathrm{CsO}$, de produção, reverta-se em antiprodução. Na medida em que se traça a linha de fuga de forma muito intensa, se o corpo desterritorializado não é preenchido por intensidades, essa linha pode se converter numa linha autoabolicionista que esvazia esse corpo, levando a um processo de desintensificação radical. Nesse esquema, o vetor deixa o quadrante superior esquerdo e se desloca rapidamente para o quadrante superior direito. Da plenitude do CsO, decorre-se o corpo esvaziado e que aos poucos pode se esvanecer. O corpo anoréxico, o corpo poroso, ou o corpo drogado. Por exemplo, as drogas, ao invés de produzir um CsO intensivo, "erigem um corpo vazio ou vitrificado, ou um corpo canceroso: a linha causal, a linha criadora ou de fuga, vira imediatamente linha de morte e de abolição" (DELEUZE; GUATTARI, 1980d, p. 80).

Nos quadrantes inferiores temos a conformação do corpo característico de nossa sociedade contemporânea, o CC. Se não está muito estratificado com um alto coeficiente de territorialização pode produzir linhas de flexibilização e quem sabe, até de desterritorialização, mantendo-se com um potencial de produção cognitiva/afetiva, constituindo linhas de segmentarização, estratos. Situa-se no quadrante inferior esquerdo. Contudo, se o coeficiente de territorialização se eleva, há uma tendência que a segmentarização dê lugar aos processos de antiprodução, havendo um rápido giro ao quadrante inferior direito. O CC tende a inchar e se fechar cada vez mais, entrando em regime de paranoia e oposição aos outros corpos. Há uma hiperterritorialização em seu próprio corpo, seja ao Eu, em regimes de códigos, as crenças religiosas, valores conservadores, a ideologia. Ocorre um recrudescimento da lógica do Eu, uma reterritorialização no ego, ou seja, um processo de erotização do Eu, que podemos chamar de egotização, isto é, os investimentos desejantes direcionados de forma centrípeta ao Eu. A egotização é um processo socialmente perigoso, pois com o recentramento e estratificação do Eu, pode fomentar processos de ruptura do laço social. Nesse sentido, a rigidez e a estratificação podem ser tamanhas, que o CC pode se calcificar e se despedaçar. Pode produzir corpos despedaçados no espaço social. Como exemplos vemos a intensificação do isolamento social, as práticas de individualismo, do fenômeno standby, a apatia social, a não sensibilidade com o Outro, e no seu limite, o ódio ao outro. E muitas vezes a clínica tradicional realiza esse fortalecimento desmedido do $\mathrm{Eu}$, principalmente em tempos de crise psicossocial, desconhecendo, ou ignorando, os percalços que com isso pode causar.

Consideramos que a intensificação das linhas abolicionista e autoabolicionista, que produzem respectivamente o CC e o corpo esvaziado resultam no esmirilhamento desses corpos. Tal precarização resulta numa outra modalidade: o corpo canceroso. Nesse sentido o corpo canceroso pode decorrer tanto de processos intensos de desterritorialização, bem como de hiperterritorialização. Ambos podem levar a pulverização desses corpos, seja por uma linha suicida, ou uma extremamente destrutiva. Corpos e órgãos que se fecham ou se abrem desmesuradamente, que atacam os outros órgãos, ou a si próprios. Há assim modalidades de precarização coletiva, no ataque e 


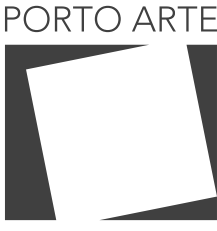

Revista de Artes Visuais

v $25 n \cdot 44$

$\mathrm{Jul} / \mathrm{dez} 2020$ e-ISSN: 2179-8001

depreciação ao outro, tal como podemos ver claramente nesse período de extremismos políticos (HUR; SABUCEDO, 2020). Os neofascismos e microfascismos podem ser vistos como o sintoma do mal-estar da sociedade contemporânea, que do alto esvaziamento, ou inchaço, produziu corpos cancerosos que estão mortificando o corpo coletivo social, e inclusive planetário-ambiental. Dessa forma, os vetores de crise social podem contribuir para o aumento da produção do CC, do corpo esvaziado e do corpo canceroso, propiciando uma necropolítica generalizada.

A clínica esquizoanalítica e esquizodramática deve operar de modo com que seus vetores de intervenção estejam direcionados para a esquerda desse esquema, numa produção de um CsO que conjugue processos de desterritorialização e reterritorialização. Deve adotar a compreensão dos riscos dos efeitos da desterritorialização radical, bem como de hiperterritorializações intensivas, mesmo que paradoxalmente os processos de desterritorialização e reterritorialização sejam seus principais instrumentos de intervenção. Portanto, deve evitar ao máximo que os processos eliciados na clínica permaneçam nos quadrantes à direita.

Esse esquema deve ser visualizado não como pontos estanques e estáticos, mas na dinâmica de seus platôs de vibração. Porque sempre estamos em zonas de vibração, de agitação, em variação contínua. 0 corpo é um campo de intensidades e o ritmo, a vibração, é um vetor de sensação, "que faz passar de um nível a outro" (DELEUZE, 1981a, p. 37). Muitas vezes o corpo está obstruído por suas estratificações, por seu organismo. Num momento pode-se estar na vibração da produção de um CsO, mas logo pode-se vibrar centripetamente como um CC. Devemos captar as vibrações das moléculas, as circulações de forças, pois são elas que modulam toda a jornada, o que sentimos, iremos fazer e falar. Destaca-se também que o que falamos, ou a mera compreensão de como vibramos, são condições necessárias, mas não suficientes para conseguir nos levar a novos platôs de intensidade, a novos processos de reinvenção social e estética.

Deste modo deve-se criar e manejar dispositivos clínico-políticos de intervenção que possam fomentar esse movimento à esquerda do esquema, no sentido da produção de um CsO, e de fuga do buraco negro do CC, da despotencialização do corpo esvaziado, ou da (auto)destruição do corpo canceroso.

\section{Considerações finais}

Nesse artigo buscamos investigar o conceito de CsO na obra de Deleuze e Guattari para traçar alguns vetores direcionais para a clínica esquizoanalítica e esquizodramática. Constatamos que o conceito de CsO se desenvolve na obra de Deleuze e Guattari, culminando em sua versão mais utilizada nos Mil Platôs. Em síntese o CsO pode ser figurado como um Ovo. Ele não é regressivo, é prospectivo, é involução, desenvolvimento entre heterogêneos, bloco, devir, multiplicidade do desejo (DELEUZE; GUATTARI, 1980c). Por isso que em sua produção, no campo da clínica, é importante que no fluir dos investimentos desejantes, consigamos cartografar, distinguir, o que remete à constituição de um plano de consistência, ou à proliferação de estratos, bem como à desestratificação demasiado violenta. São diversos tipos de movimentos que são eliciados 


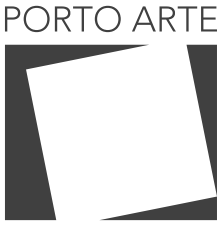

Revista de Artes Visuais

$\vee 25 n .44$

$\mathrm{Jul} / \mathrm{dez} 2020$ e-ISSN: 2179-8001

em sua propagação, decorrendo, seja num CsO intensivo, um corpo cheio, um corpo esvaziado, um corpo canceroso.

$\mathrm{Na}$ clínica esquizoanalítica e esquizodramática devemos buscar e inventar máquinas para fabricar o CsO, pois "máquinas abstractas o cuerpos sin órganos, eso es el deseo" (DELEUZE; PARNET, 1977, p. 119). E o esquizodrama é o conjunto de muitas máquinas de produção do $\mathrm{CsO}$, com diversos níveis, ou platôs, de intensidades e vibração. Seu método sempre é e será clínico-político, pois ao mesmo tempo em que se debruça na agitação das moléculas no âmbito psíquico e desejante, analisa e intervém nos vetores de forças. Sua intervenção culmina irremediavelmente nas alterações das relações de poder, seja de um coletivo em relação ao social, ou mesmo de um indivíduo consigo próprio.

Então, figuramos num esquema a dinâmica que se dá entre as distintas linhas e tipos de corpos para a produção de um CsO. Consideramos que com essa figura, são visibilizados vetores direcionais que podem contribuir como uma 'bússola' para a prática clínica, na qual possivelmente influenciem diretamente no modo de condução dos processos clínicos, bem como a escolha e operacionalização de dispositivos de intervenção.

\section{Referências}

ARTAUD, Antonin. Para acabar com o julgamento de Deus, 1947. http://escolanomade.org/wp-content/downloads/artaud-para-acabar-com-o-julgamento-de-deus.pdf

BAREMBLITT, Gregorio. Introdução à esquizoanálise. Belo Horizonte: Ed. Instituto Félix Guattari, 1988.

BAREMBLITT, Gregorio. Esquizodrama: 10 proposições descartáveis. Belo Horizonte: Ed. Instituto Gregorio Baremblitt, 2019.

BOM-TEMPO, Juliana S. \& SALMIN, Aline P. Topologias da Carne: processos criativos em dança contemporânea ou como criar para si um Corpo sem Órgãos. Revista Brasileira de Estudos da Presença, vol. 8, n. 3, p. 592-614, 2018. https://doi. org/10.1590/2237-266073137

CAETANO, Patricia L. O corpo intenso nas artes cênicas: procedimentos para o corpo sem órgãos a partir dos Bartenieff Fundamentals e do Body Mind Centering. Tese de doutorado em Teatro, Universidade Federal da Bahia, 448 f., 2012.

CORRÊA, Sandra L. Esquizoanálise: clínica e subjetividade. Avesso do Avesso, v.4, n.4, p. 33-51, 2006. http://www.feata.edu.br/downloads/revistas/avessodoavesso/ v4_artigo02_esquizoanalise.pdf

DELEUZE, Gilles. Nietzsche e a filosofia [1962]. Rio de Janeiro: Rio - Sociedade Cultural, 1976.

DELEUZE, Gilles. O bergsonismo [1966]. São Paulo: Ed. 34, 1999.

DELEUZE, Gilles. Sacher-Masoch: o frio e o cruel [1967]. Rio de Janeiro: Jorge

Zahar, 2009.

DELEUZE, Gilles. Diferença e Repetição [1968]. São Paulo: Brasiliense, 2006. 


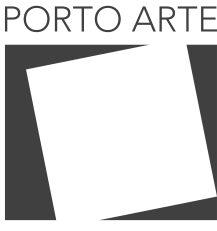

Revista de Artes Visuais

$\vee 25 n .44$ $\mathrm{Jul} / \mathrm{dez} 2020$ e-ISSN: 2179-8001
DELEUZE, Gilles. Lógica do sentido [1969]. São Paulo: Perspectiva, 2003.

DELEUZE, Gilles. Francis Bacon. Lógica da sensação [1981a]. Rio de Janeiro: Zahar, 2007.

DELEUZE, Gilles. Espinosa: Filosofia Prática [1981b]. São Paulo: Escuta, 2002.

DELEUZE, Gilles. El poder: curso sobre Foucault. [1986a]. Buenos Aires: Cactus, 2014. t. 2.

DELEUZE, Gilles. Foucault. [1986b]. São Paulo: Brasiliense, 1988.

DELEUZE, G. Conversações. São Paulo: Ed. 34, 1992.

DELEUZE, Gilles; GUATTARI, Félix. Capitalismo e Esquizofrenia: O Anti-Édipo [1972]. São Paulo, Ed. 34, 2010.

DELEUZE, Gilles; GUATTARI, Félix. Kafka: por uma literatura menor [1975]. Rio de Janeiro: Imago, 1977.

DELEUZE, Gilles; GUATTARI, Félix. Mil Platôs: Capitalismo e Esquizofrenia [1980a], vol. 1. São Paulo: Ed. 34, 1995.

DELEUZE, Gilles; GUATTARI, Félix. Mil Platôs: Capitalismo e Esquizofrenia [1980b], vol. 2. São Paulo: Ed. 34, 1995.

DELEUZE, Gilles; GUATTARI, Félix. Mil Platôs: Capitalismo e Esquizofrenia [1980c], vol. 3. São Paulo: Ed. 34, 1996.

DELEUZE, Gilles; GUATTARI, Félix. Mil Platôs: Capitalismo e Esquizofrenia [1980d], vol. 4. São Paulo: Ed. 34, 1997.

DELEUZE, Gilles; GUATTARI, Félix. Mil Platôs: Capitalismo e Esquizofrenia [1980e], vol. 5. São Paulo: Ed. 34, 1997.

DELEUZE, Gilles; PARNET, Claire. Diálogos [1977]. Valencia: Pre-textos, 2004.

GAUTHIER, Jacques. Corpo sem órgãos e bem-aventurança ambiental: por uma epistemologia da vacuidade. REMEA - Revista Eletrônica Do Mestrado Em Educação Ambiental, 25, 2013. https://doi.org/10.14295/remea.v25i0.3367

GUATTARI, Félix. ¿Qué es la Ecosofia?: textos presentados y agenciados por Stéphane Nadaud. Buenos Aires: Cactus editorial, 2015.

HUR, Domenico U. O dispositivo de grupo na Esquizoanálise: Tetravalência e Esquizodrama. Vínculo. Vol. 9, n, 1, p. 18-26, 2012. Disponível em: http://pepsic.bvsalud. org/pdf/vinculo/v9n1/a04.pdf

HUR, Domenico U. Deleuze e a constituição do diagrama de controle. Fractal: Revista de Psicologia, v. 30, n. 2, p. 173-179, 2018a. https://doi.org/10.22409/1984$0292 /$ v30i2/5507.

HUR, Domenico U. Psicologia, Política e Esquizoanálise. Campinas: Alínea, 2018b.

HUR, Domenico U.; SABUCEDO, José M. (orgs). Psicologia dos extremismos políticos. Petrópolis: Vozes, 2020.

KLEIN, Melanie; HEINMANN, Paula; ISAACS, Susan; RIVIERE, Joan. Progressos da Psicanálise. Rio de Janeiro: Zahar, 1969.

LE BON, Gustave. Psicología de las masas [1895]. Madrid: Morata, 2005.

MAOILEARCA, L. O. Como criar para si um teatro sem órgãos? Deleuze, Artaud e o conceito de Presença Diferencial. Ephemera, vol. 2, $n^{\circ}$ 3, 2019. https://periodicos. ufop.br:8082/pp/index.php/ephemera/article/view/4019/3086. 


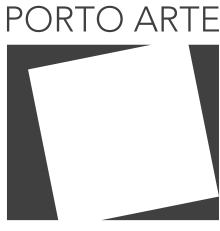

Revista de Artes Visuais

$\vee 25 n .44$ $\mathrm{Jul} / \mathrm{dez} 2020$ e-ISSN: 2179-8001

MOSSI, Cristian P.; OLIVEIRA, Marilda. Preencher potências e inventar educações possíveis: pela experimentação de uma formação-sem-órgãos. Educ. Foco, , v. 20, n. 3, p. 99-116, 2015. Disponível em https://www.lume.ufrgs.br/bitstream/handle $/ 10183 / 165005 / 001025778$.pdf?sequence=18isAllowed=y

RAMACCIOTTI, Barbara L. Deleuze: "como criar um corpo sem órgãos"? Psicanálise \& Barroco em revista, v.10, n. 2, p. 112-126, 2012. Disponível em: http://www.seer. unirio.br/index.php/psicanalise-barroco/article/viewFile/8699/7395

RANGEL, Tátia. Corpo sem Órgãos - experimentações em devir. Dissertação de mestrado em Psicologia. Universidade Federal Fluminense, 71 f., 2019. http://dx.doi. org/10.22409/PPGP.2019.m.05382859744

RESENDE, Catarina. A escrita de um corpo sem órgãos. Fractal: Revista de Psicologia, vol. 20 , n. 1 , p. $65-75,2008$. https://dx.doi.org/10.1590/S198402922008000100010

RODRIGUES, Susana, P. V. O corpo sem orgãos da arquitectura. Tese de doutorado em Arquitectura. Universidade Nova de Lisboa, 2012. Disponível em: http://hdl.handle.net/10362/10104

SAFATLE, Vladimir. Introdução à experiência intelectual de Gilles Deleuze - Aula 5: Présentation de Sacher-Masoch (manuscrito sem publicar), 2007.

SANDRINI, Elisabete G. C. Da imagem das mãos ao corpo sem órgãos: um olhar sobre a personagem Paulo Honório do romance S. Bernardo, de Graciliano Ramos. Tese de doutorado em Letras, Universidade Federal do Espírito Santo, 351 f., 2017. http://200.137.65.30/bitstream/10/9179/1/tese_11372_TESE.pdf

SCHÖPKE, Regina. Corpo sem órgãos e a produção da singularidade: A construção da máquina de guerra nômade. Rev. Filos., Aurora, v. 29, n. 46, p. 285-305, 2017. http://dx.doi.org/10.7213/1980-5934.29.046.A001

SOARES, Flávia A. O corpo anárquico na obra de Antonin Artaud: [des]encarceramento e crueldade na sociedade contemporânea. Dissertação de Mestrado em Psicologia. Universidade Federal de Goiás, 82 f., 2018. Disponível em: https://repositorio. bc.ufg.br/tede/handle/tede/8674

TEIXEIRA, Ricardo R. A Grande Saúde: uma introdução à medicina do Corpo sem Órgãos. Interface - Comunicação, Saúde, Educação, vol. 8, n. 14, p. 35-72, 2004. https://dx.doi.org/10.1590/S1414-32832004000100004

ŽIŽEK, Slavoj. Órganos sin cuerpo: Sobre Deleuze y consecuencias. Valencia: Pre-textos, 2006. 


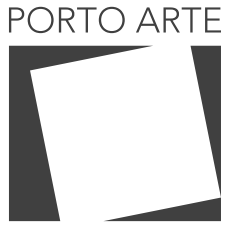

Revista de Artes Visuais

v. 25 n. 44

Jul/dez 2020 e-ISSN: 2179-8001

\section{Domenico Uhng Hur}

Psicólogo, mestre e doutor em Psicologia Social pela Universidade de São Paulo (USP), com estágio doutoral na Universidade Autônoma de Barcelona (UAB) e pós-doutorado na Universidade de Santiago de Compostela (USC- Espanha). Professor Associado da Graduação e do Programa de Pós-Graduação em Psicologia da Universidade Federal de Goiás (UFG). Bolsista de Produtividade em Pesquisa (PQ-2) do CNPq. 